\title{
Epigenetic mechanisms in migraine: a promising avenue?
}

Else Eising ${ }^{1}$, Nicole A Datson ${ }^{1}$, Arn MJM van den Maagdenberg ${ }^{1,2^{*}}$ and Michel D Ferrari ${ }^{2}$

\begin{abstract}
Migraine is a disabling common brain disorder typically characterized by attacks of severe headache and associated with autonomic and neurological symptoms. Its etiology is far from resolved. This review will focus on evidence that epigenetic mechanisms play an important role in disease etiology. Epigenetics comprise both DNA methylation and post-translational modifications of the tails of histone proteins, affecting chromatin structure and gene expression. Besides playing a role in establishing cellular and developmental stage-specific regulation of gene expression, epigenetic processes are also important for programming lasting cellular responses to environmental signals. Epigenetic mechanisms may explain how non-genetic endogenous and exogenous factors such as female sex hormones, stress hormones and inflammation trigger may modulate attack frequency. Developing drugs that specifically target epigenetic mechanisms may open up exciting new avenues for the prophylactic treatment of migraine.
\end{abstract}

Keywords: DNA methylation, epigenetics, GWAS, histone modifications, inflammation, migraine, stress, valproate

\section{Background}

Migraine is a common, disabling brain disorder typically characterized by attacks of 4 to $72 \mathrm{~h}$ of severe headache and associated autonomic and neurological symptoms [1]. In $30 \%$ of patients attacks may be preceded by neurological aura symptoms, the likely consequence of a wave of neuronal and glial depolarization called cortical spreading depression (CSD) Activation of the trigeminovascular system is responsible for migraine pain. Migraine affects over

\footnotetext{
* Correspondence: maagdenberg@lumc.nl

'Department of Human Genetics, Leiden University Medical Centre,

Einthovenweg 20, Leiden, 2333 ZC, The Netherlands

Full list of author information is available at the end of the article
}

$15 \%$ of the general population, with around $10 \%$ of migraine patients suffering from weekly attacks [2]. Current acute and prophylactic treatments are effective in less than half of the patients [2], indicating the need for more effective drugs. Identifying factors that predispose to migraine attacks is therefore crucial to provide specific molecular targets to design novel migraine drugs.

It is becoming increasingly clear that epigenetic processes play an important role in a wide variety of multifactorial diseases [3]. The question we aim to address here is: do they also play a role in migraine? Epigenetics encompasses changes to the DNA structure without changing the genetic code, resulting in chromatin remodeling and consequently affecting transcriptional potential and expression of genes. The main epigenetic modifications or 'marks' are post-translational modifications of the tails of histone proteins and DNA methylation, collectively comprising the epigenome (Figure 1). These marks are catalyzed by enzymes including histone deacetylases (HDACs), histone acetyltransferases (HATs) and DNA methyltransferases (DNMTs). Epigenetic marks can be dynamic but can also be stably inherited through cell divisions. Therefore, epigenetic processes enable cell and developmental stage-specific regulation of gene expression, but also play an important role in programming lasting responses to environmental cues.

This review highlights current evidence for an epigenetic link with migraine and speculates on neurobiological pathways that may be programmed by epigenetic mechanisms.

\section{Environmental factors and migraine}

Although there is a clear genetic component to migraine, environmental factors likely contribute approximately equally to the risk of developing migraine [4]. Environmental factors may directly trigger migraine attacks or lower the attack threshold by rendering the brain more susceptible to trigger factors. Modulators of migraine attack frequency include female sex hormones, given that migraine affects two to three times more females than males, and the occurrence is influenced by the menstrual 


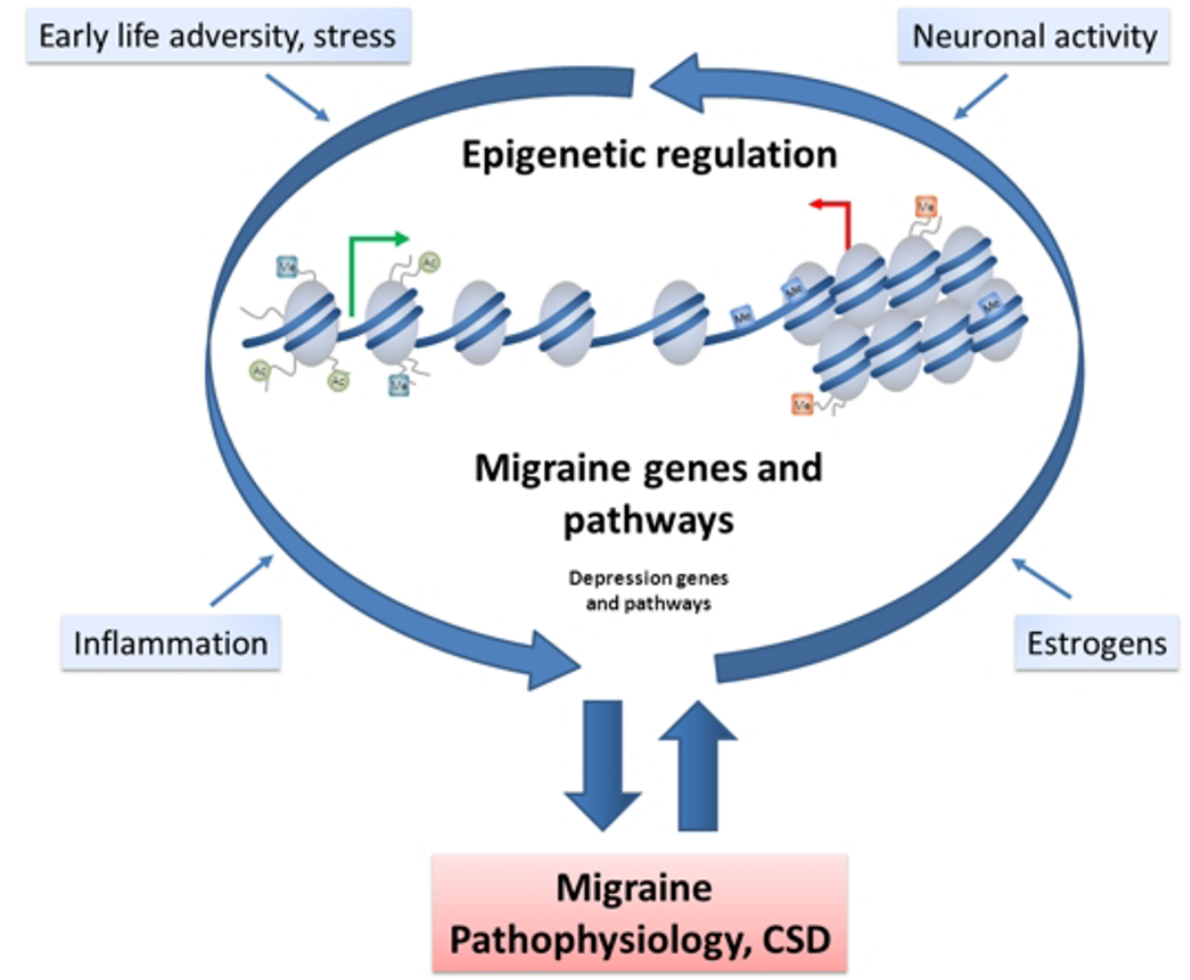

Figure 1 Proposed model in which epigenetic factors influence migraine pathophysiology. Different factors such as hormones, inflammation and neuronal activity can result in chromatin remodeling events affecting the expression of genes and pathways involved in the onset and progress of migraine and comorbid disorders such as depression. The hyperexcitability observed in migraine itself acts on the epigenome, thus creating a feed-forward loop resulting in chronification of migraine.

cycle and pregnancy, as well as by hormonal contraceptives [5]. Moreover, menopause, with its reduced estrogen and progesterone production, is associated with a decline in migraine attack frequency [6].

Animal studies have provided further evidence that female hormones can affect mechanisms directly involved in migraine pathophysiology. For instance, female transgenic migraine mice carrying a pathogenic gene mutation that causes familial hemiplegic migraine (FHM) in humans [7] have an increased susceptibility for CSD induction compared to male transgenic migraine mice [8,9]. Ovariectomy of these female migraine mice reduced the susceptibility for CSD induction, which was partially abrogated by estrogen replacement [9]. In addition, several studies in rats showed that estrogen treatment, ovariectomy as well as the menstrual cycle can alter the activity of the trigeminal nociceptive pathway [10]. The effects of female hormones are predominantly transmitted via nuclear receptors that adjust epigenetic programming of their target genes [11]. For instance, estrogen receptor $\beta$ regulates expression of glucose transporter Glut4 by maintaining a low level of DNA methylation at its promoter, thereby enabling its activation [12]. Notably, treatment of mice with an estrogen receptor $\beta$ agonist increased $\gamma$-aminobutyric acid (GABA) synthesis [13], whereas estrogen receptor $\alpha$ activation enhanced expression of astrocytic glutamate transporter Glast (also known as Slc1a3 and Eaat1) [14], thereby changing the balance between inhibitory and excitatory neurotransmission. This balance seems to be affected in migraine, resulting in increased excitatory neuronal activity, that is, creating hyperexcitability [15]. This is supported by the observation in a transgenic FHM1 mouse model that excitatory, glutamatergic, cortical neuronal activity was increased [16].

Another environmental factor that can modulate the occurrence of migraine attacks is stress. The stress system is highly sensitive to environmental programming through epigenetic mechanisms. The first study that assessed the effect of stress on the epigenome showed that low maternal care, a model for early life stress, could lastingly affect the behavior and stress responsiveness of rat offspring throughout their lifespan through increased DNA methylation at the brain-specific promoter of the glucocorticoid receptor gene $\mathrm{Nr} 4 \mathrm{a} 3$, the main receptor for glucocorticoid stress hormones [17]. Other studies have linked stress during early life as well as during 
adulthood to a wide variety of long-lasting epigenetic alterations at stress effector genes (for example, $B d n f, G r$ and $(r h)$, affecting structural and functional aspects of the brain such as stress reactivity and synaptic plasticity [18]. In migraine, short-lasting stressful periods are among the most frequently reported trigger factors [19]. Moreover, early life stress may lead to an increased risk for migraine in humans [20] and severe acute stress during adult life may promote migraine as well, given the evidence that post-traumatic-stress disorder seems to be increased in migraine patients [21]. Interestingly, early life stress is a risk factor for developing depression [22], a disorder with increased comorbidity with migraine (see below), and first evidence has also associated it with alterations of the immune system [23,24], a condition that is also associated with migraine (see below). It is therefore conceivable that stress may produce long-lasting changes in the threshold for migraine attacks by inducing epigenetic modifications throughout the brain.

\section{Epigenetics in comorbidities of migraine}

Depression and epilepsy are two disorders that display bidirectional comorbidity with migraine. Moreover, migraine is associated with an increased risk of cardiovascular disease including stroke and myocardial infarction [25]. Interestingly, depression also shares modulatory factors with migraine, such as female hormones and chronic stress, the latter of which is an established risk factor for depression [26]. A role for epigenetics has been suggested for all these comorbid disorders of migraine, and has already been extensively reviewed [27-29]. In summary, the main proof for a role of epigenetic mechanisms in depression is evident from animal models for major depressive disorder that show large changes in epigenetic programming of stress related genes (for example, $B d n f$ ) that could be reversed by antidepressant treatment $[30,31]$. Moreover, a recent study reported differential expression of DNMTs in peripheral white blood cells of patients with major depressive disorder and bipolar disorder, suggesting that aberrant epigenetic gene regulation may be associated with the pathophysiology of mood disorders [32]. The contribution of epigenetics in epilepsy is illustrated by the high occurrence of this disorder in Rett syndrome and alpha thalassemia mental retardation, two disorders caused by mutations in the epigenetic effector proteins methyl CpG binding protein 2 (MeCP2) and ATRX, respectively $[33,34]$. In addition, in the brain of temporal lobe epilepsy patients increased DNA methylation was found at the promoter of Reelin [35], a gene involved in brain plasticity whose reduced expression contributes to epilepsy pathogenesis [36]. Also in blood and tissue of cardiovascular disease patients, as well as in cardiovascular disease models, aberrant DNA methylation levels were found, both globally and at cardiovascular disease associated genes [27]. Therefore, causal pathways shared between migraine and its comorbid disorders may be modulated by epigenetic mechanisms.

\section{Epigenetics and chronification of migraine}

Attack frequency may change over the lifetime of a migraine patient and in some patients develops into chronic migraine with attacks more than 15 days per month [2]. As migraine patients with a high baseline attack frequency have an increased risk for developing chronic migraine [37], migraine attacks themselves might promote the development of chronic migraine. Additionally, recent studies have shown that synchronous neuronal activity, such as occurs during CSD, results in changes in epigenetic marks at genes involved in neuronal plasticity and neuroprotection [38-40]. This fits with evidence that epigenetic mechanisms are involved in the regulation of basal synaptic activity (that is, long-term changes in synaptic activity levels) [41]. It is, therefore, conceivable that increased neuronal activity in migraine alters the brain epigenome, thereby promoting the subsequent migraine attacks and creating a feed-forward loop (Figure 1) in which epigenetic programming of genes and pathways underlying excitability are altered towards a more sensitive baseline.

\section{Inflammation, migraine and epigenetics}

Inflammation has long been suggested to play a role in migraine. Firstly, proinflammatory cytokines are released during CSD in rat hippocampus [42]. Interestingly, inflammatory mediators can induce gene expression changes by altering epigenetic marks [43], while their expression can be inhibited by HDAC inhibitor treatment [44]. Secondly, immune mediators are involved in sensitization of nerve endings in the meninges that promote the feeling of pain [45]. This sensitization effect is the result of vasodilation and the release of proinflammatory cytokines. Prolonged inflammatory pain was shown to promote pain sensitivity by causing histone hypoacetylation at the Gad2 gene, which is involved in GABAergic signaling [46]. Therefore, migraine-related pain may cause sensitization of certain pain pathways via inflammation-induced changes in epigenetic gene regulation.

\section{Epigenetic risk factors for migraine}

Many candidate gene association studies and recently also genome-wide association studies (GWAS) have searched for genetic factors underlying migraine heritability. Some genetic factors increasing migraine susceptibility have direct links to epigenetic mechanisms. For instance, DNA polymorphisms in MTHFR (the gene for 5',10'-methylenetetrahydrofolate reductase), a gene required for DNA methylation, show a slight association with migraine in some studies [47]. More recently, GWAS have identified 
several single nucleotide polymorphisms linked to migraine pathophysiology [48-50] in genes or in regulatory regions of genes involved in epigenetic processes, including $M T D H, M E F 2 D$ and PRDM16. For example, metadherin $(\mathrm{MTDH})$ associates with nuclear factor $\kappa \mathrm{B}(\mathrm{NF} \kappa \mathrm{B})$ and a HAT to promote the expression of NF $\kappa \mathrm{B}$ target genes [51]. Myocyte enhancer factor 2D (MEF2D) can target methyltransferase complexes to specific genes to mark them for gene expression [52]. MEF2 has recently been shown to be regulated via the glucocorticoid receptor [53], which may be one of the mechanisms by which stress hormones affect the epigenome. Finally, PR domain containing 16 (PRDM16) is involved in positioning and removing specific chromatin modifications at enhancer regions of Notch target genes during olfactory neuron differentiation in drosophila [54]. These studies suggest that some of the migraine GWAS hits may contribute to developing migraine through epigenetic modifications at their target genes. Despite great efforts, GWAS have until now only explained a fraction of the total heritability of migraine. One explanation for this so-called 'missing heritability' is the fact that GWA approaches are unsuited for capturing disease susceptibility DNA variants with a low allele frequency, but which are expected to have a larger effect size [55]; next generation sequencing is currently used to identify such variants. Another possible explanation could be that DNA is not the only carrier of heritable information; epigenetic information can also be transmitted across cell divisions and possibly even transgenerationally. Recent techniques that couple array-based analysis or next generation sequencing to methods to study epigenetic marks enable genome-wide and high-throughput analysis of epigenetic marks. These techniques can analyze histone modifications (that is, by chromatin immunoprecipitation (ChIP)) as well as DNA methylation (that is, by bisulfite conversion of unmethylated cytosines or by immunoprecipitation of methylated DNA using antibodies (MeDIP) or methyl binding domains (MBD)) [56]. It therefore seems likely that the recently proposed epigenome-wide association studies, that can associate epigenetic marks to a trait (in addition to genetic variations found by GWAS) [57], will soon be put to use to further discover factors involved in migraine heritability. Because brain tissue from migraine patients is scarcely available, it may be feasible to use DNA banks consisting of large collections of stored DNA samples of migraine sufferers as a resource for identification of heritable DNA methylation marks that predispose to migraine.

\section{Potential for migraine drugs with epigenetic action}

As epigenetic regulation of gene expression is a dynamic and reversible process, it is a perfect target for drugs. Interestingly, one of the current prophylactic drugs for migraine (valproate) is a HDAC inhibitor that facilitates chromatin remodeling. Valproate is an anticonvulsive drug with many modes of action and side effects [58]; therefore, it is not certain that its beneficial effects result from its effects on the epigenome. Interestingly, valproate is also successfully used in the treatment of bipolar depression [59]. Furthermore, in animal models for depression, reduced HDAC activity is required for the restoration of the effects of chronic stress on the epigenome by antidepressant treatment [30].

While several epigenetic drugs are in clinical trials for the treatment of cancer, to date (with the exception of valproate) there are currently no epigenetic drugs that have gone into clinical trials for the treatment of neuropsychiatric disorders or migraine [60]. Developing drugs that specifically target epigenetic mechanisms in the brain will open up exciting new avenues for the prophylactic treatment of migraine.

\section{Conclusions}

Migraine is a common and disabling brain disease. Today its etiology is only partially known. In a subgroup of patients the migraine attack frequencies may dramatically increase up to near daily attacks, affecting their daily life, but the exact mechanism for chronification is unknown. Epigenetic mechanisms may underlie a part of migraine pathophysiology (and even the chronification of migraine) and therefore might provide a novel promising avenue for improving pharmacotherapy. More research is required to identify (epigenetic) targets that affect migraine pathophysiology as well as epigenetic drugs that specifically act to modulate chromatin structure at migraine pathways and can be used as a target in the prophylactic treatment for migraine.

\section{Abbreviations}

ChIP: chromatin immunoprecipitation; CSD: cortical spreading depression; DNMTs: DNA methyltransferases; GWAS: genome-wide association study; HATs: histone acetyltransferases; HDACs: histone deacetylases; MBD: methyl binding domains; MeDIP: methylated DNA immunoprecipitation.

\section{Authors' contributions}

EE carried out the literature search and drafted the manuscript. NAD conceived the concept and design of the commentary, helped to draft the manuscript and revised it critically. AMJMvdM and MDF read and critically revised the manuscript. MDF initiated development of this commentary. All authors read and approved the final manuscript.

\section{Competing interests}

The authors declare that they have no competing interests.

\section{Author details}

'Department of Human Genetics, Leiden University Medical Centre, Einthovenweg 20, Leiden, 2333 ZC, The Netherlands. ${ }^{2}$ Department of Neurology, Leiden University Medical Centre, Albinusdreef 2, Leiden, 2333 ZA, The Netherlands.

Received: 9 October 2012 Accepted: 4 February 2013 Published: 4 February 2013 
References

1. IHS: The International Classification of Headache Disorders. Cephalalgia 2 2004, 24(Suppl 1):9-160

2. Goadsby PJ, Lipton RB, Ferrari MD: Migraine-current understanding and treatment. N Engl J Med 2002, 346:257-270.

3. Portela A, Esteller M: Epigenetic modifications and human disease. Nat Biotechnol 2010, 28:1057-1068.

4. Wessman M, Terwindt GM, Kaunisto MA, Palotie A, Ophoff RA: Migraine: a complex genetic disorder. Lancet Neurol 2007, 6:521-532.

5. MacGregor EA: Oestrogen and attacks of migraine with and without aura. Lancet Neurol 2004, 3:354-361.

6. Freeman EW, Sammel MD, Lin H, Gracia CR, Kapoor S: Symptoms in the menopausal transition: hormone and behavioral correlates. Obstet Gynecol 2008, 111:127-136.

7. Ophoff RA, Terwindt GM, Vergouwe MN, van Eijk R, Oefner PJ, Hoffman SM, Lamerdin JE, Mohrenweiser HW, Bulman DE, Ferrari M, Haan J, Lindhout D, van Ommen GJ, Hofker MH, Ferrari MD, Frants RR: Familial hemiplegic migraine and episodic ataxia type- 2 are caused by mutations in the $\mathrm{Ca}^{2}$ + channel gene CACNL1A4. Cell 1996, 87:543-552.

8. van den Maagdenberg AM, Pietrobon D, Pizzorusso T, Kaja S, Broos LA, Cesetti T, van de Ven RC, Tottene A, van der Kaa J, Plomp JJ, Frants RR, Ferrari MD: A Cacna1a knockin migraine mouse model with increased susceptibility to cortical spreading depression. Neuron 2004, 41:701-710.

9. Eikermann-Haerter K, Dilekoz E, Kudo C, Savitz SI, Waeber C, Baum MJ, Ferrari MD, van den Maagdenberg AM, Moskowitz MA, Ayata C: Genetic and hormonal factors modulate spreading depression and transient hemiparesis in mouse models of familial hemiplegic migraine type 1. J Clin Invest 2009, 119:99-109.

10. Gupta S, McCarson KE, Welch KM, Berman NE: Mechanisms of pain modulation by sex hormones in migraine. Headache 2011, 51:905-922.

11. Green CD, Han JD: Epigenetic regulation by nuclear receptors. Epigenomics 2011, 3:59-72.

12. Ruegg J, Cai W, Karimi M, Kiss NB, Swedenborg E, Larsson C, Ekstrom TJ, Pongratz I: Epigenetic regulation of glucose transporter 4 by estrogen receptor beta. Mol Endocrinol 2011, 25:2017-2028.

13. Tan XJ, Dai YB, Wu WF, Kim HJ, Barros RP, Richardson TI, Yaden BC Warner M, McKinzie DL, Krishnan V, Gustafsson JA: Reduction of dendritic spines and elevation of GABAergic signaling in the brains of mice treated with an estrogen receptor beta ligand. Proc Natl Acad Sci USA 2012, 109:1708-1712

14. Lee ES, Sidoryk M, Jiang $H$, Yin Z, Aschner M: Estrogen and tamoxifen reverse manganese-induced glutamate transporter impairment in astrocytes. J Neurochem 2009, 110:530-544.

15. Aurora SK, Wilkinson F: The brain is hyperexcitable in migraine. Cephalalgia 2007, 27:1442-1453.

16. Tottene A, Conti R, Fabbro A, Vecchia D, Shapovalova M, Santello M, van den Maagdenberg AM, Ferrari MD, Pietrobon D: Enhanced excitatory transmission at cortical synapses as the basis for facilitated spreading depression in $\mathrm{Ca}(\mathrm{v}) 2.1$ knockin migraine mice. Neuron 2009, 61:762-773.

17. Weaver IC, Cervoni N, Champagne FA, D'Alessio AC, Sharma S, Seckl JR, Dymov S, Szyf M, Meaney MJ: Epigenetic programming by maternal behavior. Nat Neurosci 2004, 7:847-854.

18. Hunter RG: Epigenetic effects of stress and corticosteroids in the brain. Front Cell Neurosci 2012, 6:18.

19. Kelman L: The triggers or precipitants of the acute migraine attack. Cephalalgia 2007, 27:394-402

20. Tietjen GE, Peterlin BL: Childhood abuse and migraine: epidemiology, sex differences, and potential mechanisms. Headache 2011, 51:869-879.

21. Peterlin BL, Nijjar SS, Tietjen GE: Post-traumatic stress disorder and migraine: epidemiology, sex differences, and potential mechanisms. Headache 2011, 51:860-868.

22. Heim C, Binder EB: Current research trends in early life stress and depression: review of human studies on sensitive periods, geneenvironment interactions, and epigenetics. Exp Neurol 2012, 233:102-111.

23. Tietjen GE, Khubchandani J, Herial NA, Shah K: Adverse childhood experiences are associated with migraine and vascular biomarkers. Headache 2012, 52:920-929.

24. Danese A, Pariante CM, Caspi A, Taylor A, Poulton R: Childhood maltreatment predicts adult inflammation in a life-course study. Proc Natl Acad Sci USA 2007, 104:1319-1324.
25. Diener HC, Kuper M, Kurth T: Migraine-associated risks and comorbidity. J Neurol 2008, 255:1290-1301.

26. Holsboer F: The corticosteroid receptor hypothesis of depression. Neuropsychopharmacology 2000, 23:477-501.

27. Udali S, Guarini P, Moruzzi S, Choi SW, Friso S: Cardiovascular epigenetics: From DNA methylation to microRNAs. Mol Aspects Med 2012.

28. Qureshi IA, Mehler MF: Epigenetic mechanisms underlying human epileptic disorders and the process of epileptogenesis. Neurobiol Dis 2010, 39:53-60.

29. Sun H, Kennedy PJ, Nestler EJ: Epigenetics of the depressed brain: role of histone acetylation and methylation. Neuropsychopharmacology 2013, 38:124-137.

30. Tsankova NM, Berton O, Renthal W, Kumar A, Neve RL, Nestler EJ: Sustained hippocampal chromatin regulation in a mouse model of depression and antidepressant action. Nat Neurosci 2006, 9:519-525.

31. Wilkinson MB, Xiao G, Kumar A, LaPlant Q, Renthal W, Sikder D, Kodadek TJ, Nestler EJ: Imipramine treatment and resiliency exhibit similar chromatin regulation in the mouse nucleus accumbens in depression models. $J$ Neurosci 2009, 29:7820-7832.

32. Higuchi F, Uchida S, Yamagata H, Otsuki K, Hobara T, Abe N, Shibata T, Watanabe Y: State-dependent changes in the expression of DNA methyltransferases in mood disorder patients. J Psychiatr Res 2011, 45:1295-1300.

33. Amir RE, Van den Veyver IB, Wan M, Tran CQ, Francke U, Zoghbi HY: Rett syndrome is caused by mutations in X-linked MECP2, encoding methylCpG-binding protein 2. Nat Genet 1999, 23:185-188.

34. Gibbons R: Alpha thalassaemia-mental retardation, X linked. Orphanet $J$ Rare Dis 2006, 1:15

35. Kobow K, Jeske I, Hildebrandt M, Hauke J, Hahnen E, Buslei R, Buchfelder M, Weigel D, Stefan H, Kasper B, Pauli E, Blumcke I: Increased reelin promoter methylation is associated with granule cell dispersion in human temporal lobe epilepsy. J Neuropathol Exp Neurol 2009, 68:356-364

36. Haas CA, Frotscher M: Reelin deficiency causes granule cell dispersion in epilepsy. Exp Brain Res 2010, 200:141-149.

37. Scher Al, Stewart WF, Ricci JA, Lipton RB: Factors associated with the onset and remission of chronic daily headache in a population-based study. Pain 2003, 106:81-89.

38. Passaro D, Rana G, Piscopo M, Viggiano E, De Luca B, Fucci L: Epigenetic chromatin modifications in the cortical spreading depression. Brain Res 2010, 1329:1-9.

39. Rana G, Donizetti A, Virelli G, Piscopo M, Viggiano E, De Luca B, Fucci L: Cortical spreading depression differentially affects lysine methylation of $\mathrm{H} 3$ histone at neuroprotective genes and retrotransposon sequences. Brain Res 2012, 1467:113-119.

40. Guo JU, Ma DK, Mo H, Ball MP, Jang MH, Bonaguidi MA, Balazer JA, Eaves HL, Xie B, Ford E, Zhang K, Ming GL, Gao Y, Song H: Neuronal activity modifies the DNA methylation landscape in the adult brain. Nat Neurosci 2011, 14:1345-1351.

41. Nelson ED, Monteggia LM: Epigenetics in the mature mammalian brain: effects on behavior and synaptic transmission. Neurobiol Learn Mem 2011, 96:53-60.

42. Kunkler PE, Hulse RE, Kraig RP: Multiplexed cytokine protein expression profiles from spreading depression in hippocampal organotypic cultures. J Cereb Blood Flow Metab 2004, 24:829-839.

43. Johnson HM, Noon-Song EN, Kemppainen K, Ahmed CM: Steroid-like signalling by interferons: making sense of specific gene activation by cytokines. Biochem J 2012, 445:295.

44. Xuan A, Long D, Li J, Ji W, Hong L, Zhang M, Zhang W: Neuroprotective effects of valproic acid following transient global ischemia in rats. Life Sci 2012, 90:463-468

45. Waeber C, Moskowitz MA: Migraine as an inflammatory disorder. Neurology 2005, 64:S9-15

46. Zhang Z, Cai YQ, Zou F, Bie B, Pan ZZ: Epigenetic suppression of GAD65 expression mediates persistent pain. Nat Med 2011, 17:1448-1455.

47. Schurks M, Rist PM, Kurth T: MTHFR 677C > T and ACE D/I polymorphisms in migraine: a systematic review and meta-analysis. Headache 2010, 50:588-599.

48. Anttila V, Stefansson $H$, Kallela M, Todt U, Terwindt GM, Calafato MS Nyholt DR, Dimas AS, Freilinger T, Muller-Myhsok B, Artto V, Inouye M, Alakurtti K, Kaunisto MA, Hamalainen E, de Vries B, Stam AH, Weller CM, 
Heinze A, Heinze-Kuhn K, Goebel I, Borck G, Gobel H, Steinberg S, Wolf C, Bjornsson A, Gudmundsson G, Kirchmann M, Hauge A, Werge T, et al: Genome-wide association study of migraine implicates a common susceptibility variant on 8q22.1. Nat Genet 2010, 42:869-873.

49. Chasman DI, Schurks M, Anttila V, de Vries B, Schminke U, Launer L, Terwindt GM, van den Maagdenberg AM, Fendrich $K$, Volzke H, Ernst F, Griffiths LR, Buring JE, Kallela M, Freilinger T, Kubisch C, Ridker PM, Palotie A, Ferrari MD, Hoffmann W, Zee RY, Kurth T: Genome-wide association study reveals three susceptibility loci for common migraine in the general population. Nat Genet 2011, 43:695-698.

50. Freilinger T, Anttila V, de Vries B, Malik R, Kallela M, Terwindt GM, PozoRosich P, Winsvold B, Nyholt DR, van Oosterhout WP, Artto V, Todt U, Hamalainen E, Fernandez-Morales J, Louter MA, Kaunisto MA, Schoenen J, Raitakari O, Lehtimaki T, Vila-Pueyo M, Gobel H, Wichmann E, Sintas C, Uitterlinden AG, Hofman A, Rivadeneira F, Heinze A, Tronvik E, van Duijn CM, Kaprio J, et al: Genome-wide association analysis identifies susceptibility loci for migraine without aura. Nat Genet 2012, 44:777-782.

51. Sarkar D, Park ES, Emdad L, Lee SG, Su ZZ, Fisher PB: Molecular basis of nuclear factor-kappaB activation by astrocyte elevated gene-1. Cancer Res 2008, 68:1478-1484.

52. Rampalli S, Li L, Mak E, Ge K, Brand M, Tapscott SJ, Dilworth FJ: p38 MAPK signaling regulates recruitment of Ash2L-containing methyltransferase complexes to specific genes during differentiation. Nat Struct Mol Biol 2007, 14:1150-1156.

53. Speksnijder N, Christensen KV, Didriksen M, De Kloet ER, Datson NA: Glucocorticoid receptor and myocyte enhancer factor 2 cooperate to regulate the expression of c-Jun in a neuronal context. J Mol Neurosc 2012, 48:209-218.

54. Endo K, Karim MR, Taniguchi H, Krejci A, Kinameri E, Siebert M, Ito K, Bray SJ, Moore AW: Chromatin modification of Notch targets in olfactory receptor neuron diversification. Nat Neurosci 2012, 15:224-233.

55. Manolio TA, Collins FS, Cox NJ, Goldstein DB, Hindorff LA, Hunter DJ, McCarthy MI, Ramos EM, Cardon LR, Chakravarti A, Cho JH, Guttmacher AE, Kong A, Kruglyak L, Mardis E, Rotimi CN, Slatkin M, Valle D, Whittemore AS, Boehnke M, Clark AG, Eichler EE, Gibson G, Haines JL, Mackay TF, McCarroll SA, Visscher PM: Finding the missing heritability of complex diseases. Nature 2009, 461:747-753.

56. Ku CS, Naidoo N, Wu M, Soong R: Studying the epigenome using next generation sequencing. J Med Genet 2011, 48:721-730.

57. Rakyan VK, Down TA, Balding DJ, Beck S: Epigenome-wide association studies for common human diseases. Nat Rev Genet 2011, 12:529-541.

58. Johannessen Landmark C: Antiepileptic drugs in non-epilepsy disorders: relations between mechanisms of action and clinical efficacy. CNS Drugs 2008, 22:27-47.

59. Smith LA, Cornelius VR, Azorin JM, Perugi G, Vieta E, Young AH, Bowden CL: Valproate for the treatment of acute bipolar depression: systematic review and meta-analysis. J Affect Disord 2010, 122:1-9.

60. Peedicayil J, Kumar A: Time for clinical trials of epigenetic drugs in psychiatric disorders? Br J Clin Pharmacol 2012, 73:309-310.

\section{Pre-publication history}

The pre-publication history for this paper can be accessed here: http://www.biomedcentral.com/1741-7015/11/26/prepub

\section{doi:10.1186/1741-7015-11-26}

Cite this article as: Eising et al:: Epigenetic mechanisms in migraine: a promising avenue? BMC Medicine 2013 11:26.

\section{Submit your next manuscript to BioMed Central and take full advantage of:}

- Convenient online submission

- Thorough peer review

- No space constraints or color figure charges

- Immediate publication on acceptance

- Inclusion in PubMed, CAS, Scopus and Google Scholar

- Research which is freely available for redistribution

Submit your manuscript at www.biomedcentral.com/submit 